\title{
Isotopic effects of nitrate photochemistry in snow: a field study at Dome C, Antarctica
}

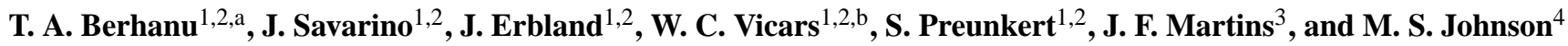 \\ ${ }^{1}$ Universite Grenoble Alpes, LGGE, 38041 Grenoble, France \\ ${ }^{2}$ CNRS, LGGE, 38000 Grenoble, France \\ ${ }^{3}$ LTHE, UMR 5564, UJF-Grenoble 1/CNRS-INSU/G-INP, 38041 Grenoble, France \\ ${ }^{4}$ Copenhagen Center for Atmospheric Research, Department of Chemistry, University of Copenhagen, \\ Universitetsparken 5, 2100 Copenhagen $\varnothing$, Denmark \\ ${ }^{a}$ currently at: Physics Institute, Climate and Environmental Physics, University of Bern, 3012 Bern, Switzerland \\ b currently at: Technical Services Program, Air Pollution Control Division, Colorado Department of Public Health and \\ Environment, Denver, CO, USA
}

Correspondence to: J. Savarino (joel.savarino@ujf-grenoble.fr)

Received: 5 November 2014 - Published in Atmos. Chem. Phys. Discuss.: 23 December 2014

Revised: 29 June 2015 - Accepted: 18 September 2015 - Published: 9 October 2015

\begin{abstract}
Stable isotope ratios of nitrate preserved in deep ice cores are expected to provide unique and valuable information regarding paleoatmospheric processes. However, due to the post-depositional loss of nitrate in snow, this information may be erased or significantly modified by physical or photochemical processes before preservation in ice. We investigated the role of solar UV photolysis in the postdepositional modification of nitrate mass and stable isotope ratios at Dome C, Antarctica, during the austral summer of 2011/2012. Two $30 \mathrm{~cm}$ snow pits were filled with homogenized drifted snow from the vicinity of the base. One of these pits was covered with a plexiglass plate that transmits solar UV radiation, while the other was covered with a different plexiglass plate having a low UV transmittance. Samples were then collected from each pit at a $2-5 \mathrm{~cm}$ depth resolution and a 10-day frequency. At the end of the season, a comparable nitrate mass loss was observed in both pits for the top-level samples $(0-7 \mathrm{~cm})$ attributed to mixing with the surrounding snow. After excluding samples impacted by the mixing process, we derived an average apparent nitrogen isotopic fractionation $\left({ }^{15} \varepsilon_{\text {app }}\right)$ of $-67.8 \pm 12 \%$ for the snow nitrate exposed to solar UV using the nitrate stable isotope ratios and concentration measurements. For the control samples in which solar UV was blocked, an apparent average ${ }^{15} \varepsilon_{\text {app }}$ value of $-12.0 \pm 1.7 \%$ was derived. This difference strongly suggests that solar UV photolysis plays a dominant
\end{abstract}

role in driving the isotopic fractionation of nitrate in snow. We have estimated a purely photolytic nitrogen isotopic fractionation $\left({ }^{15} \varepsilon_{\text {photo }}\right)$ of $-55.8 \pm 12.0 \%$ ofrom the difference in the derived apparent isotopic fractionations of the two experimental fields, as both pits were exposed to similar physical processes except exposure to solar UV. This value is in close agreement with the ${ }^{15} \varepsilon_{\text {photo }}$ value of $-47.9 \pm 6.8 \%$ o derived in a laboratory experiment simulated for Dome $\mathrm{C}$ conditions (Berhanu et al., 2014). We have also observed an insensitivity of ${ }^{15} \varepsilon$ with depth in the snowpack under the given experimental setup. This is due to the uniform attenuation of incoming solar UV by snow, as ${ }^{15} \varepsilon$ is strongly dependent on the spectral distribution of the incoming light flux. Together with earlier work, the results presented here represent a strong body of evidence that solar UV photolysis is the most relevant post-depositional process modifying the stable isotope ratios of snow nitrate at low-accumulation sites, where many deep ice cores are drilled. Nevertheless, modeling the loss of nitrate in snow is still required before a robust interpretation of ice core records can be provided. 


\section{Introduction}

Nitrate $\left(\mathrm{NO}_{3}^{-}\right)$, the end product of the oxidation of atmospheric nitrogen oxides $\left(\mathrm{NO}_{x}=\mathrm{NO}+\mathrm{NO}_{2}\right)$, is one of the most abundant ions present in polar ice and snow. Ice core nitrate mass and isotopic measurements have the potential to provide quantitative constraints on historic variations in atmospheric $\mathrm{NO}_{x}$ cycling and oxidative capacity (Legrand and Kirchner, 1990; Wolff, 1995). However, the interpretation of these paleorecords is problematic at most sites on the polar ice sheets, where post-depositional processes such as the desorption of nitrate species on snow grains, sublimation or condensation of water vapor and photolysis of nitrate have a major influence on the signal archived in firn and ice (Dibb et al., 1998; Honrath et al., 1999; Röthlisberger et al., 2002; Blunier et al., 2005; Frey et al., 2009; Wolff, 2013). While desorption is manifested by the physical release of $\mathrm{HNO}_{3}$ from the snowpack, photolysis involves bond breaking in $\mathrm{NO}_{3}^{-}$and emission of the photoproducts, such as $\mathrm{NO}_{x}, \mathrm{HONO}$ and the hydroxyl radical $(\mathrm{OH})$, which can alter the oxidative capacity of the overlying atmosphere (Chen et al., 2001; Crawford et al., 2001; Domine and Shepson, 2002; Grannas et al., 2007; Meusinger et al., 2014).

The stable isotope ratios of nitrate are useful metrics used to constrain $\mathrm{NO}_{x}$ chemistry (Savarino et al., 2007, 2013; Morin et al., 2008; Hastings et al., 2009; Vicars et al., 2013) and the post-depositional processing of nitrate in snow (Blunier et al., 2005; Frey et al., 2009; Erbland et al., 2013). Stable isotope ratios $(R)\left(n\left({ }^{18} \mathrm{O}\right) / n\left({ }^{16} \mathrm{O}\right), n\left({ }^{17} \mathrm{O}\right) / n\left({ }^{16} \mathrm{O}\right)\right.$ and $\left.n\left({ }^{15} \mathrm{~N}\right) / n\left({ }^{14} \mathrm{~N}\right)\right)$ are expressed as isotopic enrichments or depletion $\left(\delta^{18} \mathrm{O}, \Delta \Delta^{17} \mathrm{O}\right.$ and $\left.\delta^{15} \mathrm{~N}\right)$ relative to a reference where $\delta=\left(R_{\text {spl }} / R_{\text {ref }}\right)-1$ and $R$ represents the elemental ${ }^{17} \mathrm{O} /{ }^{16} \mathrm{O},{ }^{18} \mathrm{O} /{ }^{16} \mathrm{O}$ or ${ }^{15} \mathrm{~N} /{ }^{14} \mathrm{~N}$ ratio in the sample or reference material. The $\Delta^{17} \mathrm{O}$ value is defined here using the linear relation of $\Delta^{17} \mathrm{O}=\delta^{17} \mathrm{O}-0.52 \times \delta^{18} \mathrm{O}$. The reference used for oxygen isotope analysis is Standard Mean Oceanic Water (SMOW) and the reference for nitrogen is atmospheric $\mathrm{N}_{2}$. For practical reasons, $\delta$ values are typically reported in per mill (\%o), as variations in isotopic ratios for natural samples occur within a very narrow range.

In order to constrain post-depositional effects on the concentration and stable isotope ratios of nitrate, it is necessary to know about the isotopic fractionation values (expressed using ${ }^{15} \varepsilon,{ }^{18} \varepsilon,{ }^{17} E$; see Eq. 1 for definitions), which are unique for each post-depositional process. Blunier and coworkers analyzed two surface ice cores from Dome C, Antarctica, and determined a nitrogen isotopic fractionation $\left({ }^{15} \varepsilon\right)$ of $-54 \pm 10 \%$ (Blunier et al., 2005). In an attempt to reproduce this field observation in the laboratory, artificial snow was irradiated with UV light in the $200-900 \mathrm{~nm}$ wavelength range and a ${ }^{15} \varepsilon$ value of $-11.7 \pm 1.4 \%$ was determined. The authors concluded that post-depositional modification must therefore result primarily from sublimation of snow and/or from desorption of nitric acid, with only a minor contribution from photolysis. However, it was later con- firmed that the light source used in this laboratory study possessed a different spectral distribution compared to solar spectra encountered in the field, and this may have had a confounding effect on the interpretation of the results (Frey et al., 2009). This effect was shown experimentally in a recent laboratory study (Berhanu et al., 2014; Meusinger et al., 2014) by irradiating natural snow from Dome $\mathrm{C}$ using different UV filters to match field conditions. Accordingly, isotopic fractionations became less negative and approached 0 when irradiated with short wavelength UV light and vice versa due to the different overlaps of nitrate isotopologue cross sections with the incoming UV. The ${ }^{15} \varepsilon$ value of $-47.9 \pm 6.8 \%$ o derived for the experiment conducted using a $320 \mathrm{~nm}$ filter (closer to Dome C solar irradiance conditions) was in good agreement with the field observations of $-54 \pm 10 \%$ (Blunier et al., 2005), $-50 \pm 10$ and $-71 \pm 12 \%$ oby Frey et al. (2009) at Dome C. A recent field study by Erbland and colleagues determined an average apparent ${ }^{15} \varepsilon$ value of $-59 \pm 10 \%$ for the East Antarctic Plateau (Erbland et al., 2013).

A theoretical framework has been developed by Frey and colleagues in order to determine isotopic fractionations associated with photolysis (Frey et al., 2009). The authors used the zero point energy shift model ( $\triangle \mathrm{ZPE}$ ) (Yung and Miller, 1997), convoluted with a solar spectrum measured during the summer solstice at Dome $\mathrm{C}$, and determined a ${ }^{15} \varepsilon$ value of $-48 \%$, consistent with their field observations. However, photolytic isotopic fractionations based solely on the ZPE shift model are affected by the limitations of the model, such as ignoring the change in shape and intensity of the absorption cross sections during isotopic substitutions (Schmidt et al., 2011). In a recent study, a semiempirical model was developed that is based on the ZPE shift model but addresses some of the limitations mentioned above (Berhanu et al., 2014). This model enabled a better estimation of the absorption cross sections of nitrate isotopologues, which can be interpolated to a temperature of interest, thus providing a better estimate for isotopic fractionations under field conditions.

The currently existing field studies (Blunier et al., 2005; Frey et al., 2009; Erbland et al., 2013) derived apparent isotopic fractionations (denoted ${ }^{15} \varepsilon_{\text {app }},{ }^{18} \varepsilon_{\text {app }}$ and ${ }^{17} E_{\text {app }}$ ) that incorporate not only the isotopic effects of photolysis but also other processes with the potential to induce isotopic fractionation (desorption, reoxidation and surface deposition). In addition, the isotopic fractionations obtained in the existing field studies cover a wide range of ${ }^{15} \varepsilon$ values ( -40 to $-74.3 \%$ o) (Erbland et al., 2013). Therefore, further experimental and modeling studies are required to constrain the effects of photolysis on stable isotope ratios of nitrate in snow and to advance the interpretation of these measurements in snow and ice.

We performed a field study at Concordia (Dome C), Antarctica, $\left(75^{\circ} 06^{\prime} \mathrm{S}, 123^{\circ} 19^{\prime} \mathrm{E}\right)$ during the Antarctic summer of 2011/2012. The effect of UV photolysis on snow nitrate and its associated effects on nitrate's stable isotopic composition were investigated. We have employed an iso- 
lation technique to produce UV-exposed and limited UVexposed samples in order to understand the role of photolysis in the post-depositional processing of snow nitrate. To the best of our knowledge, this is the first field study that has employed an isolation strategy to constrain specifically nitrate mass loss and the isotopic fractionation induced by photolysis from solar UV radiation.

\section{Methods}

\subsection{Experimental design}

Windblown snow (i.e., drifted snow) was collected at Dome C on 2 December 2011 and physically homogenized in the field. This drifted snow possessed a high nitrate concentration $(\approx 1450 \mathrm{ppb})$, which ensured levels adequate for isotopic analysis. As the snow density was not measured, its value can be estimated to be about 225 to $330 \mathrm{~kg} \mathrm{~m}^{-3}$ based on its faceted-grain-like structure (Gallet et al., 2011). Two snow pits of $1 \mathrm{~m} \times 2 \mathrm{~m}$ surface area and $30 \mathrm{~cm}$ depth were excavated within close proximity $(\sim 10 \mathrm{~m})$ and filled with the drifted homogenized snow. A rectangular wooden frame was used to mark each surface level at a fixed position (i.e., depth $=0 \mathrm{~cm}$ ). Any additional windblown snow accumulating above this wooden mark could be removed on a weekly basis or as necessary. The snow did not become hardened with time during the study period. The pits were covered with plexiglass plates of different UV transmittances (Fig. 1), one having only minor transmittance $(10-15 \%)$ below $380 \mathrm{~nm}$, and the other allowing most of the solar UV radiation in the 290-380 nm range. Transmittance was measured as a ratio between incoming solar light below the plexiglass plate to light on top of the plate. Note that sometimes light reflected back by the snow might lead to transmittance greater than 1 . For simplicity, the samples exposed to UV will be referred to as "UV" samples, while those collected from the other pit, which was expected to be unaffected by UV-driven photolysis, will be referred to as "control" samples. Note that other non-UV-light-associated effects are expected to affect both pits equally (e.g., the disturbance of outgoing long-wave radiation caused by the plates). Equally, it should be realized that complete protection from UV radiation in the field is impossible due to the scattering of light by the snow, high solar zenithal angles ( $\mathrm{min}$ at solstice $51.6^{\circ}$ ) and imperfect UV cutting by the plexiglass. Such interferences are too complex to quantify but are mainly limited to the first few centimeters of snow. The choice of the plexiglass plate transmittance was based on the UV absorption cross section of nitrate. Nitrate has UV absorption peaks around 200 and $305 \mathrm{~nm}$, with the former being 3 orders of magnitude stronger than the latter (Mack and Bolton, 1999). However, light at the wavelengths of the strong $200 \mathrm{~nm}$ band is cut off because of the presence of the stratospheric ozone layer (Fig. 2) and does not reach Earth's surface. The control plexiglass plate blocks

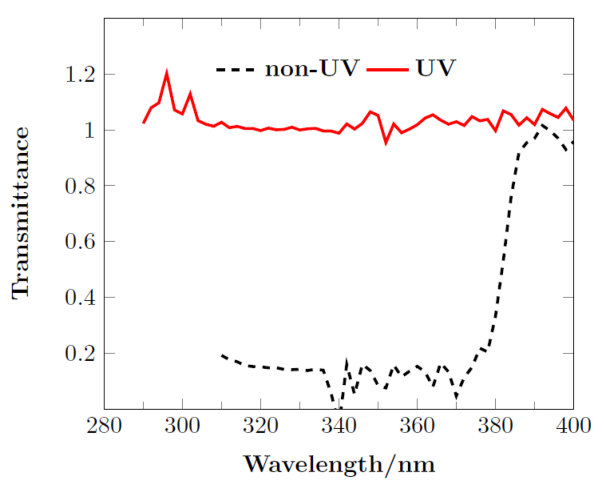

Figure 1. Transmittance as measured for the control and the UV plates. The UV plate transmits solar UV above $290 \mathrm{~nm}$, whereas the control plate has a cutoff at ca. $375 \mathrm{~nm}$ (note that the control plate has an average transmittance of $15 \%$ below $375 \mathrm{~nm}$ ). As transmission was measured as the ratio between solar light below plexiglass plate to light above the plexiglass plate, light reflected back by the snow might lead to transmittance greater than 1 .

the secondary absorption band in contrast to the UV plexiglass plates, which allow this band to reach the snow beneath. The plexiglass plates were placed on a metallic frame $20 \mathrm{~cm}$ above the snow surface, which was expected to be an optimum height because it minimizes both the warming effect on the snow beneath and the trapping of emitted $\mathrm{NO}_{x}$ photoproducts. Placing the plates at a higher level could increase the possibility of snow deposition at the sides; furthermore, at higher solar zenith angles there may be solar UV radiation reaching the control plates. However, vertical plates were not placed at the sides to avoid trapping drifted snow.

\subsection{Sampling and concentration measurements}

Sampling was conducted every 10 days from 2 December 2011 to 30 January 2012 at a $2-5 \mathrm{~cm}$ depth resolution and to a depth of $30 \mathrm{~cm}$. Samples were collected less frequently at depths below the homogenized snow (i.e., down to $50 \mathrm{~cm}$ ). The individual sampling events are indicated using numbers $0-6$, with the numbers increasing from the beginning to the end of the season. Below $50 \mathrm{~cm}$, the photolysis of nitrate becomes negligible, as demonstrated by the light transmission measured at Dome C (France et al., 2011). The detailed sampling dates are given in Table 1. Sampling was usually conducted in the morning between 09:00 and 12:00 LT and, on a few occasions, one pit was sampled in the morning and another in the afternoon. During sampling the plexiglass plates were removed so that both pits were exposed to direct solar UV for a short period of time (usually less than $1 \mathrm{~h}$ ). For each sample, a snow mass of $0.3-0.6 \mathrm{~kg}$ was collected, placed into a $2 \mathrm{~L}$ Whirl-Pack ${ }^{\mathrm{TM}}$ bag and stored frozen (note that in a few cases, a larger amount of snow, up to $1 \mathrm{~kg}$ was collected). The vertical pipes created during sampling were backfilled using natural snow from nearby, 
Table 1. Sample IDs with their respective sampling dates during the Austral summer 2011/2012 field campaign at Dome C, Antarctica.

\begin{tabular}{ll}
\hline Sample ID & Sampling date \\
\hline UV no. 0 and control no. 0 & 2 Dec 2011 \\
UV no. 1 and control no. 1 & 10 Dec 2011 \\
UV no. 2 and control no. 2 & 21 Dec 2011 \\
UV no. 3 and control no. 3 & 31 Dec 2011 \\
UV no. 4 and control no. 4 & 10 Jan 2012 \\
UV no. 5 and control no. 5 & 20 Jan 2012 \\
UV no. 6 and control no. 6 & 30 Jan 2012 \\
\hline
\end{tabular}

with a different nitrate concentration and isotopic signature than the experimental snow. A mark was left on the wooden frame after each sampling to record the place where sampling was conducted. A gap of $10 \mathrm{~cm}$ was left between consecutive samplings to ensure that subsequent samplings were not modified by previous samplings. The samples were later melted at room temperature for nitrate concentration measurement and preconcentration. The concentration of nitrate in each sample was determined in a warm laboratory at the Dome $\mathrm{C}$ station using a continuous flow analysis method. This is a fast technique used in previous studies by our group at Dome $\mathrm{C}$, with a precision of better than $3 \%$ and a detection limit of $5 \mathrm{ng} \mathrm{g}^{-1}$ (Frey et al., 2009; Erbland et al., 2013). In this study, we have determined a precision of better than $5 \%$ based on replicate standard measurements. Most of the melted snow sample volume was preconcentrated using an anion exchange resin AG 1-X8 (Bio-Rad 200-400 mesh chloride form) to trap $\mathrm{NO}_{3}^{-}$for isotopic analysis. This step is essential to ensure that enough samples are available for replicate measurements. The nitrate trapped in the resin was eluted with the addition of $5 \times 2 \mathrm{~mL} 1 \mathrm{M} \mathrm{NaCl}$ solution (Frey et al., 2009; Erbland et al., 2013). The samples were stored in plastic tubes in the dark and shipped frozen to Grenoble, France, for isotopic analysis. We have also collected surface snow samples along with the snow pit sampling in the immediate vicinity in order to follow possible mixing of the surrounding snow with the snow pits. The analysis of these samples was conducted in a similar fashion as for the snow pit samples.

\subsection{Isotopic analysis}

The oxygen and nitrogen isotopic composition of nitrate was determined using the bacterial denitrifier method (Sigman et al., 2001; Casciotti et al., 2002; Kaiser et al., 2007; Morin et al., 2008) as modified by Kaiser et al. (2007) and Morin et al. (2009). Briefly, a culture of the denitrifying bacteria (Pseudomonas aureofaciens) was concentrated 8 times by centrifugation following a 5-7-day growth period. $2 \mathrm{~mL}$ of the bacterial culture were then transferred to a $20 \mathrm{~mL}$ glass vial, which was sealed airtight with a PTFE septum. The vials were then degassed for $3 \mathrm{~h}$ using a helium flow (Air Liquide,
99.999\%). Using an automated system (Gilson Liquid Handler 215), $100 \mathrm{nmol}$ of each preconcentrated nitrate sample was then injected into these vials. After an overnight incubation, which allows for complete conversion of $\mathrm{NO}_{3}^{-}$to $\mathrm{N}_{2} \mathrm{O}$ (Sigman et al., 2001), $0.5 \mathrm{~mL}$ of $1 \mathrm{M} \mathrm{NaOH}$ was added to each vial to inactivate the bacterial cells. The $\mathrm{N}_{2} \mathrm{O}$ in the sample vial headspace was then flushed with purified helium $(99.999 \%)$, cryogenically trapped before being transferred into a gold tube at $900{ }^{\circ} \mathrm{C}$, where it was decomposed to $\mathrm{O}_{2}$ and $\mathrm{N}_{2}$ (Cliff and Thiemens, 1994; Kaiser et al., 2007), which were separated by a GC (gas chromatograph) column and passed into a MAT253 IRMS (isotope ratio mass spectrometer) (Thermo Scientific) to determine the stable oxygen and nitrogen isotope ratios (Morin et al., 2009).

To correct for isotopic effects associated with sample analysis, we have included certified standards of USGS-32, USGS-34 and USGS-35 (Michalski et al., 2002; Bohlke et al., 2003), which were subjected to a treatment identical to the samples and prepared in the same matrix $(1 \mathrm{M} \mathrm{NaCl}$ solution prepared using Dome $\mathrm{C}$ water in order to match the oxygen isotopic composition of local water) (Werner and Brand, 2001; Morin et al., 2009). We have determined the overall accuracy of the method as the standard deviation of the residuals derived from the linear regression between the measured and expected values of the reference materials (Morin et al., 2009). For the samples analyzed in this study, the associated overall accuracies are 2.0, 0.4 and $0.6 \%$ or $\delta^{18} \mathrm{O}, \Delta^{17} \mathrm{O}$ and $\delta^{15} \mathrm{~N}$, respectively.

\subsection{Data reduction}

In order to quantify the effect of photolysis on the stable isotope ratios of snow nitrate, we have calculated apparent isotopic fractionations (isotopic fractionations derived for field samples irrespective of the process inducing fractionation) for $\mathrm{O}$ and $\mathrm{N}$ isotopes $\left({ }^{15} \varepsilon_{\text {app }},{ }^{18} \varepsilon_{\text {app }}\right.$ and ${ }^{17} E_{\text {app }}$ for $\delta^{15} \mathrm{~N}$, $\delta^{18} \mathrm{O}$ and $\Delta^{17} \mathrm{O}$ of nitrate, respectively). In doing so, we assume an open system, where $\mathrm{NO}_{x}$ emitted upon the photolysis of nitrate will be removed as soon as it is formed and nitrate at depth is considered irreversibly lost (in contrast to the "skin layer" snow, which receives the deposition of reoxidation products) and adopt the linear relation used in previous studies (Blunier et al., 2005; Erbland et al., 2013):

$\ln (\delta+1)=\varepsilon \ln (f)+\ln \left(\delta_{0}+1\right)$,

where $f$ is the nitrate fraction remaining in snow, defined as the ratio of the final nitrate concentration $(C)$ and the initial nitrate concentration $\left(C_{0}\right)$ in the snow $\left(f=C / C_{0}\right) . \delta_{0}$ and $\delta$ are the isotope ratio values for the initial and final snow, respectively. Due to a hiatus in preparing the standards for each batch of analysis (an offset was observed between batches but not within a batch), the use of the initial concentration of the homogenized snow as the starting point was not possible. Instead $C_{0}$ was calculated using the average nitrate concentration measured at a depth of $25-30 \mathrm{~cm}$, assuming there is 
no change in the amount of nitrate at this depth due to insufficient light penetration and the short duration of the experiment. The slope of the $\ln (\delta+1)$ vs. $\ln (f)$ plot is the isotopic fractionation $\varepsilon$ (note that $\varepsilon=(\alpha-1)$ ), where $\alpha$ is the fractionation factor.

Isotopic fractionation due to photolysis (denoted ${ }^{15} \varepsilon_{\text {photo }}$ ) has also been determined in this study using $\triangle \mathrm{ZPE}$ and the light transmittance of plexiglass plates, as described in Frey et al. (2009). According to this model, during isotopic substitution, the ZPE of the heavier isotopologue is reduced, leading to a small blue shift in the absorption spectrum of the heavier isotopologue relative to the lighter one (Fig. 2). Hence, from a light isotopologue with a measured absorption cross section $\left({ }^{14} \mathrm{NO}_{3}^{-}\right)$, it is possible to derive the absorption cross section of the heavier isotopologue $\left({ }^{15} \mathrm{NO}_{3}^{-}\right.$) (Yung and Miller, 1997; Miller, 2000). Isotopic fractionations $(\varepsilon)$ were determined using the following equation:

$\varepsilon=\frac{J^{\prime}}{J}-1$,

where $J^{\prime}$ and $J$ are the photolytic rate constants of the heavier and lighter isotopologues, respectively, defined mathematically as

$J=\int \varphi(\lambda, T) \sigma(\lambda, T) I(\lambda, \theta, z) \mathrm{d} \lambda$
$J^{\prime}=\int \varphi(\lambda, T) \sigma^{\prime}(\lambda, T) I(\lambda, \theta, z) \mathrm{d} \lambda$,

where $\sigma$ and $\sigma^{\prime}$ are the absorption cross sections of the light and heavy isotopologues, respectively. $\varphi(\lambda)$ is the quantum yield and $I$ is the actinic flux for the given wavelength ranges, which depends on the solar zenith angle $(\theta)$ and snow depth $(z)$. Note that if $\varphi(\lambda)$ is assumed to be independent of wavelength and is the same both for ${ }^{14} \mathrm{NO}_{3}^{-}$and ${ }^{15} \mathrm{NO}_{3}^{-}$, then there is no need to know its value in order to determine the isotopic fractionation value. In this study, we have applied this principle and derived isotopic fractionations for the UV-exposed pit in the presence of the plexiglass plates for field conditions.

We have also investigated the depth dependence of the isotopic fractionation using the concentration and isotope ratio profiles of nitrate in the experimental snow pits. Accordingly, samples from the same depths from the seven sampling events were stacked together, and isotopic fractionations were determined from the measured nitrate concentration and $\delta^{15} \mathrm{~N}$ applying the Rayleigh plot approximation. Sampling at exactly the same depth during each collection was not possible under field conditions; therefore, the nitrate concentration and $\delta^{15} \mathrm{~N}$ values obtained for at least four different samples that were expected to be at the same depth, were used to derive the isotopic fractionation values. In a few cases, samples within a $1 \mathrm{~cm}$ depth range were averaged together to derive ${ }^{15} \varepsilon$.

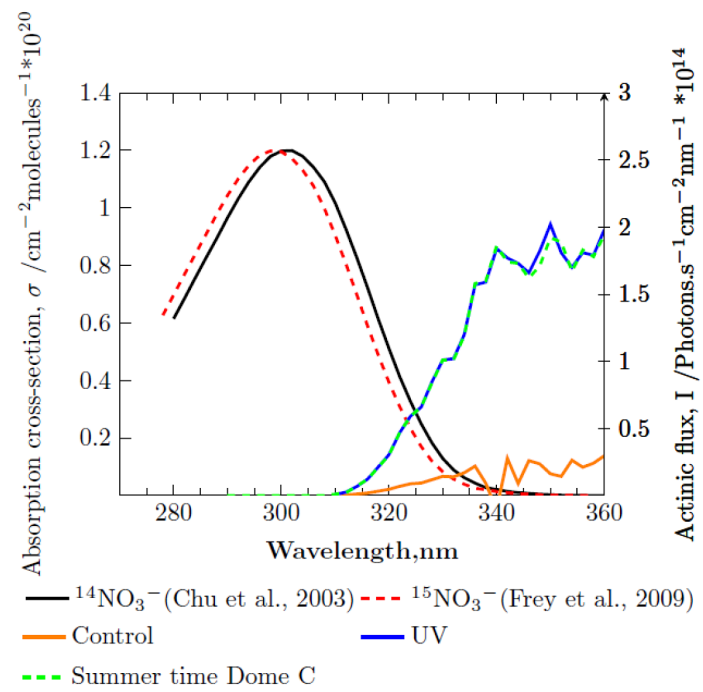

Figure 2. The absorption cross section of ${ }^{14} \mathrm{NO}_{3}^{-}$measured in the liquid phase and the absorption cross section of ${ }^{15} \mathrm{NO}_{3}^{-}$determined using the ZPE shift model (left $y$ axis). The absorption cross section of ${ }^{15} \mathrm{NO}_{3}^{-}$was derived by applying an average shift of $0.5 \mathrm{~nm}$ on ${ }^{14} \mathrm{NO}_{3}^{-}$. The $2 \mathrm{~nm}$ shift has been manually emphasized (note that in reality the two curves nearly overlap). Plotted on the right $y$ axis is the solar spectrum derived using the TUV (Tropospheric Ultraviolet Visible) model at Dome $\mathrm{C}$ conditions (ozone column depth of 297 DU and an albedo of 0.9) and expected UV fluxes in the presence of the plexiglass plate filters.

\subsection{Experimental precautions}

It is important to present the precautions taken in this study to minimize possible artifacts. The two experimental fields were open to the atmosphere despite the presence of the plexiglass plates. Therefore, while the deposition of snow and/or nitrate was prevented at the top of the experimental fields, drifted snow could still have been deposited at the surface of the pits, as the sides were not closed, in addition to dry deposition of gaseous $\mathrm{HNO}_{3}$. In order to minimize the effect from drifted snow, we mounted a wooden frame at the sides of the snow pits so that it was possible to establish a reference surface level $($ depth $=0 \mathrm{~cm})$, and the snow present above this frame was carefully removed as necessary. In addition, in order to avoid absorption or reflection of solar UV by windblown snow deposited on top of the plexiglass plates, we cleaned the plates at least once a week. However, during strong winds and bad weather, it was impossible to precisely maintain the reference frame location. The lack of homogeneity within and between fields and possible dry deposition are unavoidable sources of mixing and noise in the data obtained from this experiment, especially for the first few centimeters of the pits. 

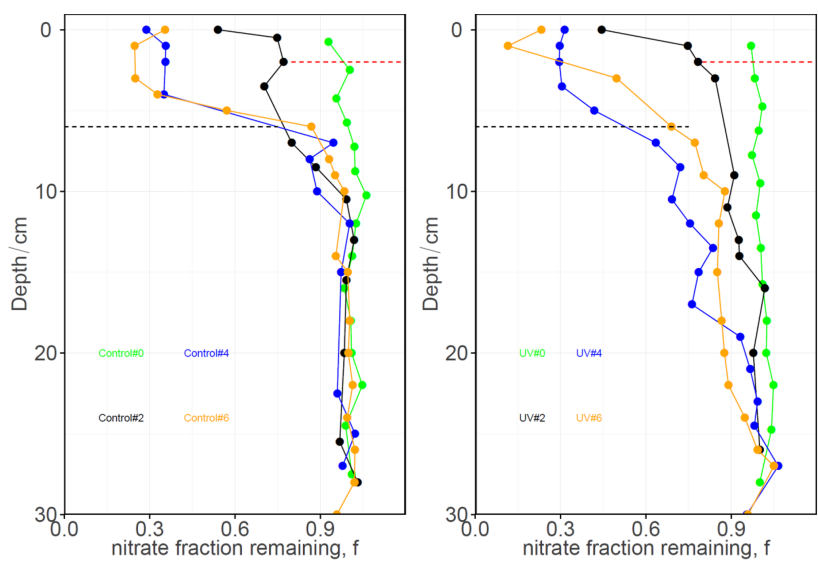

Figure 3. Plot of the nitrate fraction remaining in the snow $(f)$ with depth. Control samples (reduced solar UV) are plotted in the left panel and UV-exposed samples are plotted in the right panel. The numbers denote the sampling events, which were carried out at 10-day intervals from 2 December 2011 to 30 January 2012. The dashed lines show the depth where external factors (mainly mixing) play a significant role.

\section{Results}

\subsection{Concentration profiles}

Figure 3 shows the fraction of nitrate remaining in the snow for each field and for each sampling events. (The actual nitrate concentrations for the entire sampling events are shown in Fig. 1 of the Supplement.) Accordingly, at the beginning of the experiment (Turnbull et al., 2015, and control no. 0, $t=0$ ), the concentration of nitrate was uniform with depth $(f \approx 1)$. This corresponds to an average nitrate concentration of $1431 \pm 46.8$ and $1478 \pm 34.5 \mathrm{ng} \mathrm{g}^{-1}$ down to a $30 \mathrm{~cm}$ depth for the control and UV pits, respectively.

For control no. 2, $f$ is about 0.75 in the top $5 \mathrm{~cm}$, but the profile stabilized below $10 \mathrm{~cm}$, with $f \approx 1$. A significant nitrate change was observed for the controls no. 4 and no. 6 when compared to controls no. 0 and no. 2 , with $f$ reaching $0.15-0.25$ in the top $4 \mathrm{~cm}$, but higher $f$ values $(f>0.8)$ were observed below $5 \mathrm{~cm}$. The maximum nitrate change $(f<0.3)$ was observed at the surface. It is important to note that the change observed in the uppermost centimeters is not necessarily the result of a mass loss but could also result from mixing with surrounding snow with a lower nitrate concentration than the experimental snow, resulting in an apparent mass loss.

In contrast, samples from the pit exposed to UV radiation showed a decrease in nitrate mass up to a depth of $20 \mathrm{~cm}$. For UV no. 2 , a nitrate change of $f \approx 0.5$ was observed at the surface. However, at lower depths, below $3 \mathrm{~cm}$, only minor changes were observed $(f>8)$. The maximum nitrate change, with $f$ reaching 0.2 , was observed for UV no. 4 and UV no. 6. The decrease continued up to a depth of $7 \mathrm{~cm}$

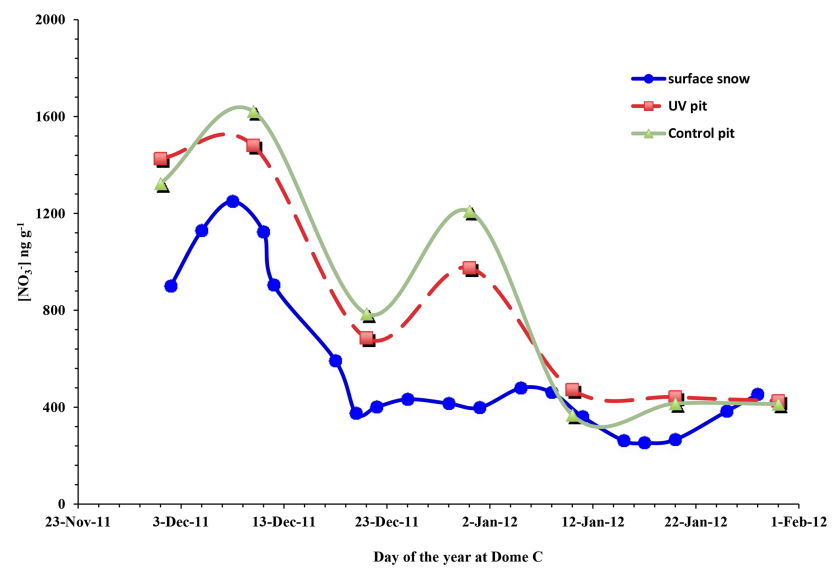

Figure 4. The nitrate concentration profile for the surface snow collected in the vicinity of the two pits compared with the UV and control pit surface snow (0-2 cm depth).

where $f$ reached 0.4. Further minor decrease $(f>0.75)$ was observed up to a depth of $20 \mathrm{~cm}$, and the decrease in nitrate ceased below $25 \mathrm{~cm}$.

In general, the decrease in nitrate in the top $7 \mathrm{~cm}$ was comparable for both the control and UV samples (a further indication of a possible mixing process); however, the amount of nitrate mass decrease was different in each pit depending on depth and collection date.

For the surface snow samples, we observed nitrate concentrations as high as $1500 \mathrm{ng} \mathrm{g}^{-1}$ in mid-December that decreased to $400 \mathrm{ng} \mathrm{g}^{-1}$ at the end of January (Fig. 4). This concentration profile sometimes matches the concentration of nitrate measured at a depth of $0-2 \mathrm{~cm}$ in the snow pits, which may have been caused by mixing and/or substitution by the surrounding snow.

\subsection{Isotopic analysis}

Figure 5 shows the $\delta^{15} \mathrm{~N}$ profiles of the two pits for samples no. 0 , no. 2 , no. 4 and no. 6 (the $\delta^{15} \mathrm{~N}$ values for the duration of the sampling season are shown in Fig. 3 of the Supplement). Controls no. 0 and no. 2 showed fairly uniform $\delta^{15} \mathrm{~N}$, with values ranging between -10 and $0 \%$. However, controls no. 4 and 6 were enriched in $\delta^{15} \mathrm{~N}$ up to $+15 \%$ o for the surface samples ( $0-2 \mathrm{~cm}$ depth) extending to a depth of about $7 \mathrm{~cm}$ and subtle changes below a depth of $10 \mathrm{~cm}$.

In the case of the UV samples, only UV no. 0 showed stability up to $30 \mathrm{~cm}$ depth, with $\delta^{15} \mathrm{~N}$ values ranging between -6 and $-8 \%$. For the top $5 \mathrm{~cm}$ samples of UV no. 2, the $\delta^{15} \mathrm{~N}$ values showed an increase, with a maximum value at the surface $(+12 \% \circ)$ and a stable $\delta^{15} \mathrm{~N}$ profile below a depth of $5 \mathrm{~cm}$. Comparable $\delta^{15} \mathrm{~N}$ values and similar profiles were observed for UV no. 4 and UV no. 6 , with a maximum $\delta^{15} \mathrm{~N}$ value of $+35 \%$ at a depth of $2-4 \mathrm{~cm}$. However, a decrease in $\delta^{15} \mathrm{~N}$ towards the surface was observed, and this profile is not consistent for all samples. All of the UV samples (excluding 

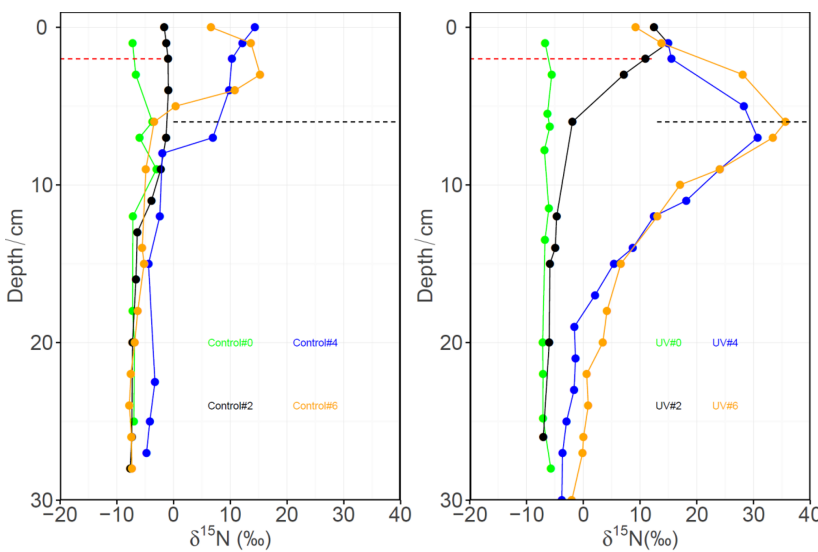

Figure 5. $\delta^{15} \mathrm{~N}$ depth profiles for snow nitrate in the control (left panel) and UV (right panel) pits. The horizontal lines show the depth where mixing is present in samplings nos. 0-2 (red) and 4-6 (black) in both pits.

UV no. 0) have decreasing $\delta^{15} \mathrm{~N}$ values from their respective maximum value to about +8 to $+14 \%$ o near the snow surface (ca. $0-2 \mathrm{~cm}$ ), irrespective of the sampling time. Meanwhile, this pattern is also apparent for controls no. 4 and 6 .

For the surrounding surface snow samples, $\delta^{15} \mathrm{~N}$ values varying between -10 and $+40 \%$ were measured on different days (Fig. 6). However, no trend was observed in the $\delta^{15} \mathrm{~N}$ values over time. These values are sometimes similar to what is measured at the surface of the two pits; consequently, we believe that the first $7 \mathrm{~cm}$ in both pits was subjected to mixing with the surrounding snow.

Figure 7 shows the $\delta^{18} \mathrm{O}$ values obtained for both the control and UV samples, which ranged from 52 to $68 \%$. It is difficult to detect a consistent trend between $\delta^{18} \mathrm{O}$ and depth or sampling period for either the control or UV samples in this data set.

Similar to the $\delta^{18} \mathrm{O}$ observations, the measured $\Delta^{17} \mathrm{O}$ values also exhibited no significant trend, with values between 26 and 30\%o obtained for both pits (Fig. 8). However, comparing the control and UV samples, more variability is observed in the $\Delta^{17} \mathrm{O}$ values of the UV samples.

In general, when comparing the stable oxygen isotope ratios of the control and UV samples, it is difficult to identify any pattern or significant difference between the two sets with respect to sampling event (Figs. 7 and 8). However, a significant difference is observed between the two pits (control and UV) for $\delta^{15} \mathrm{~N}$. The measured $\delta^{15} \mathrm{~N}$ values are the main results, used in this study to understand the role of photolysis in the post-depositional processing of snow nitrate.

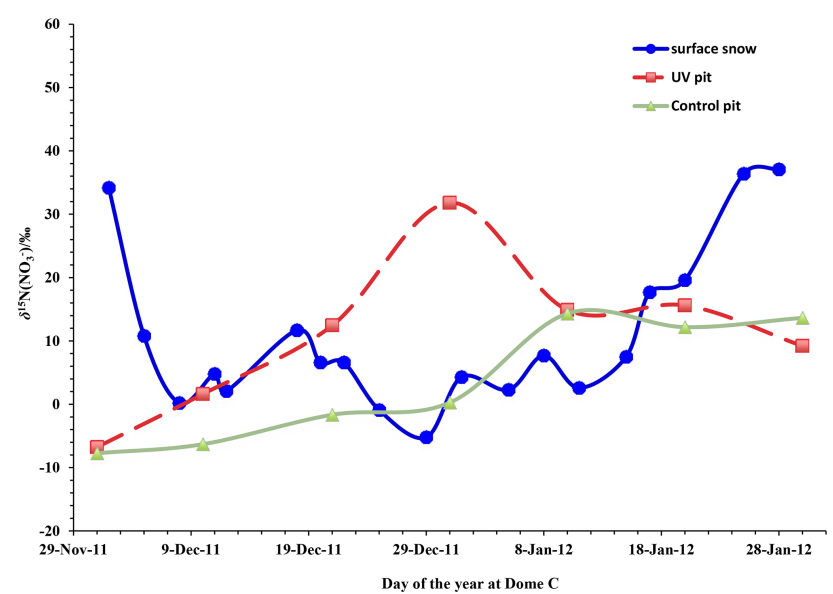

Figure 6. $\delta^{15} \mathrm{~N}$ time series for nitrate in natural surface snow compared to surface snow sampled from the UV and control pits.

\section{Discussion}

\subsection{Processes possibly affecting the top $0-7 \mathrm{~cm}$}

As this experimental study is based on the comparison of results obtained from two pits filled with the same drifted snow, our first priority was to ensure that the two pits were as identical as possible at the beginning of the study to minimize or possibly prevent non-photolytic process. Figures 3 and 5 show a uniform nitrate mass fraction left in the snow $(f \approx 1)$ as well as a fairly stable $\delta^{15} \mathrm{~N}$ ( -6 to $-8 \%$ ) profile up to a depth of $30 \mathrm{~cm}$ for both UV no. 0 and control no. 0 . This observation indicates that the snow was well homogenized and both pits had comparable initial nitrate concentrations and isotopic compositions. However, Figs. 3 and 5 show a significant change in nitrate and enrichment in $\delta^{15} \mathrm{~N}$ was observed in the top $0-7 \mathrm{~cm}$ after consecutive sampling events, even in the absence of direct solar UV light. This observation, together with the decreasing $\delta^{15} \mathrm{~N}$ pattern observed near the surface layers with opposite direction to the expected enrichment at similar depths, implies that additional processes besides photolysis may be involved at these depths. Based on this observation and as a first approach, we have divided the two pits into two regions: the top 0-7 cm samples, where photolysis, mixing and additional processes are expected to act strongly, and samples collected at a depth of $7-30 \mathrm{~cm}$, where the effect of these additional processes is minor and photolysis is the dominant process inducing nitrate mass loss and isotopic fractionation. We have discussed below the possible causes for nitrate mass loss in the top $7 \mathrm{~cm}$, which are summarized in Fig. 9.

Dome C generally experiences moderate wind speeds, with an average value of $2.9 \mathrm{~m} \mathrm{~s}^{-1}$ throughout the 1984 2003 meteorological record (Aristidi et al., 2005; Zhou et al., 2009), but even in this range of wind speeds, deposition and erosion of snow are possible at the surface. Even 

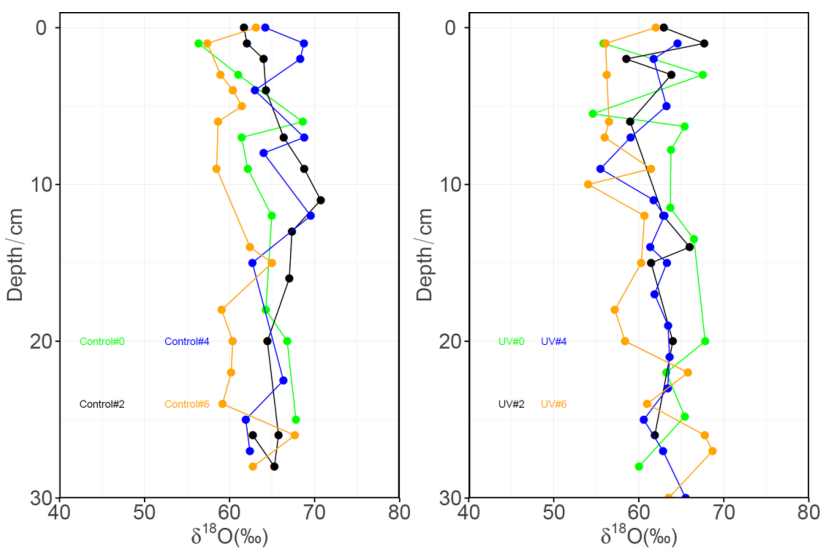

Figure 7. $\delta^{18} \mathrm{O}$ depth profiles for snow nitrate in the control (left panel) and UV (right panel) pits.
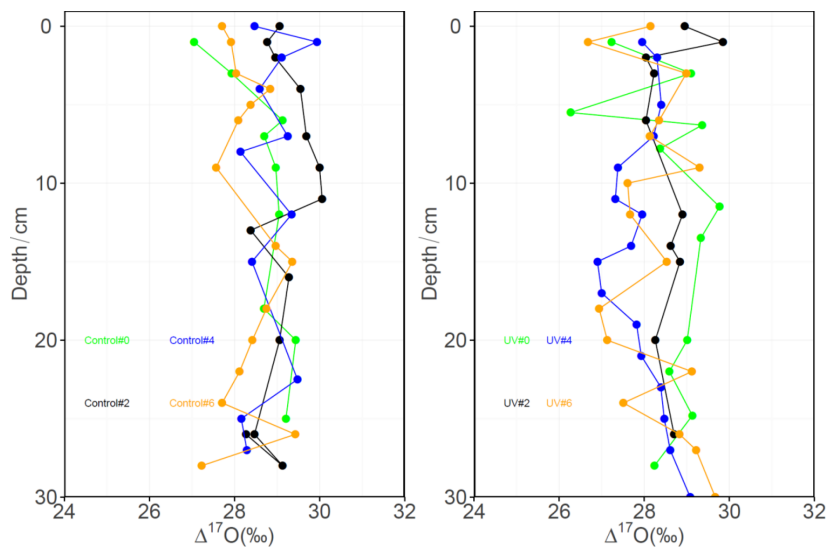

Figure 8. Same as Fig. 7 but for $\Delta^{17} \mathrm{O}$.

though the new snow deposited above the reference surface level was removed once or twice a week, the snow might have already been mixed with the underlying surface layer and manual removal may have disturbed or mixed the two layers, even with extremely careful handling. Furthermore, erosion and replacement are also expected to take place during strong wind events. In addition, the drifted snow on the surface of the two pits was not always evenly deposited; more snow was often deposited on one pit relative to the other, and the deposition was not homogeneous even within a single pit. This variability could have led to changes in the surface reference level between each sampling event and may have thus introduced additional artifacts in these samples.

Snowfall was not observed during the sampling period; therefore, wet deposition of nitrate via snowfall can be excluded. However, dry deposition of $\mathrm{HNO}_{3}$ is still possible even with the plates in place. An interesting observation was the convergence in both the nitrate concentration and $\delta^{15} \mathrm{~N}$ values among the surface snow samples from the different batches. For the surface snow pit samples, both of these values converge on $f \approx 0.3$ and $\delta^{15} \mathrm{~N} \approx+10$ to $+14 \%$ (mainly

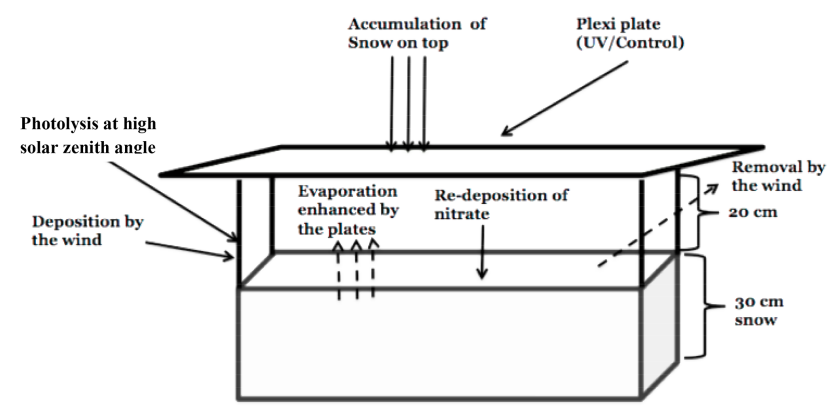

Figure 9. Schematic showing the possible external processes that could affect the surface layers of both the UV and control pits. These include evaporation, wind deposition and/or removal and photolysis at high solar zenith angle.

in UV nos. 2-6 and controls no. 4-6 samples), as can be seen in Figs. 3 and 5. These values contradict expectations based on the concentration and $\delta^{15} \mathrm{~N}$ profile observed below $7 \mathrm{~cm}$. This implies that there might be snow deposition or mixing at the surface of the pits with snow with lower nitrate concentration (Fig. 4) and a different isotopic composition $\left(\delta^{15} \mathrm{~N} \approx+10\right.$ to +14$)$, giving a false impression of mass loss. As these measured values are sometimes in agreement with the surface snow measurements from a similar time period (Fig. 6), the presence of deposition is inevitable. For example, on 10 January 2012 we observed drifted snow on both snow pits (see Supplement) with similar nitrate concentration and stable isotope ratios as the nearby surface snow measurement. However, such events were sporadic and apparently depended on meteorological conditions.

Another important process to consider is the redeposition of nitrate via dry deposition. $\mathrm{NO}_{x}$ photoproducts can be locally reoxidized to reform nitrate and eventually redeposited on the snow surface. It should also be noted that desorption may have taken place from the surface of both of the pits, which could be enhanced by the plexiglass plates trapping heat and warming the top layers. This effect should be manifested in both pits and should affect mainly the top few centimeters of the snow. The pits exhibited comparable loss of nitrate mass in the top $7 \mathrm{~cm}$, but the $\delta^{15} \mathrm{~N}$ values were significantly different for the two pits, with minimum $\delta^{15} \mathrm{~N}$ values of -15.0 and $-36.0 \%$ for the control and UV pit samples, respectively. However, the more highly negative isotopic fractionation observed for the UV samples was probably due to the dominance of photolysis over the nonphotolytic processes present in both pits.

Another possible reason for the observed nitrate mass change and resulting isotopic effect could be photolysis in both pits. The plexiglass plate over the control pit excluded the majority of UV light at wavelengths shorter than $380 \mathrm{~nm}$. However, 10-20\% of the incoming solar UV in the range of $300-310 \mathrm{~nm}$ is transmitted through this plate (Fig. 1), thus resulting in a spectral distribution in the control pit that over- 
laps with the nitrate UV absorption band. Additionally, at higher solar zenith angles, there might be direct solar UV impeding upon the sides of the plexiglass plates leading to photolysis.

In general, there are multiple processes (Fig. 9) that can alter the concentration and isotopic composition of nitrate in the top $7 \mathrm{~cm}$ of snow. Identifying these processes and quantifying them is beyond the scope of this study. Hence, in this manuscript the samples from the $7-30 \mathrm{~cm}$ depth range will be mainly considered with a few exceptions when results are consistent with a unidirectional process.

\subsection{Isotopic fractionations}

Due to an insignificant change in nitrate mass and isotopic composition, the linear fits for samples no. 0 and no. 1 from both pits were only weakly correlated and are not discussed. Better correlations were observed for samples collected late in the season.

\subsubsection{The nitrogen isotopic fractions: ${ }^{15} \varepsilon$}

The calculated nitrogen isotopic fractionation values (i.e., the slopes of the Rayleigh plots, correlation coefficients and $p$ values) for samples between depths of 7 and $30 \mathrm{~cm}$ in the control and UV pits are given in Table 2. Figure 10 shows the ${ }^{15} \varepsilon_{\text {app }}$ values determined for the control and UV samples collected below $7 \mathrm{~cm}$. Accordingly, the control samples possessed nearly constant and small negative apparent isotopic fractionation values between $-7.4 \pm 2.3$ and $-15 \pm 0.9 \%$ o. In contrast, the UV samples shown in Fig. 10 exhibited higher negative apparent nitrogen isotopic fractionations ranging from $-18.0 \pm 7.3$ to $-58.3 \pm 20.0 \%$, which became progressively more negative over time. According to this figure, it seems that either ${ }^{15} \varepsilon$ evolves over time (i.e., from collection event no. 2 to no. 6), which contradicts theory (Berhanu et al., 2014), or there is an artifact introduced by removing the samples collected in the top $7 \mathrm{~cm}$, where relatively larger nitrate mass change and isotopic fractionation were observed. An artifact due to removing all the samples at a depth of $0-7 \mathrm{~cm}$ is the most probable as samples from this depth exhibited maximal nitrate loss (about $80 \%$ nitrate is lost) and significant enrichment in $\delta^{15} 15 \mathrm{~N}$ when compared to samples below $7 \mathrm{~cm}$. In addition, the depth where the abovementioned processes affect the surface snow may not be homogeneous in space and time. Hence, a new approach is followed using the nitrate $\delta^{15} \mathrm{~N}$ signal to identify data points that may be impacted by one or more of the processes explained above. Accordingly, the bending pattern in $\delta^{15} \mathrm{~N}$ observed for samples near the surface layers implies either the presence of another process or contamination by windblown snow with a different isotopic composition. As this bending pattern is inconsistent with a Rayleigh type process, we have excluded the samples from the surface level when the $\delta^{15} \mathrm{~N}$ begins to decrease instead of increasing to

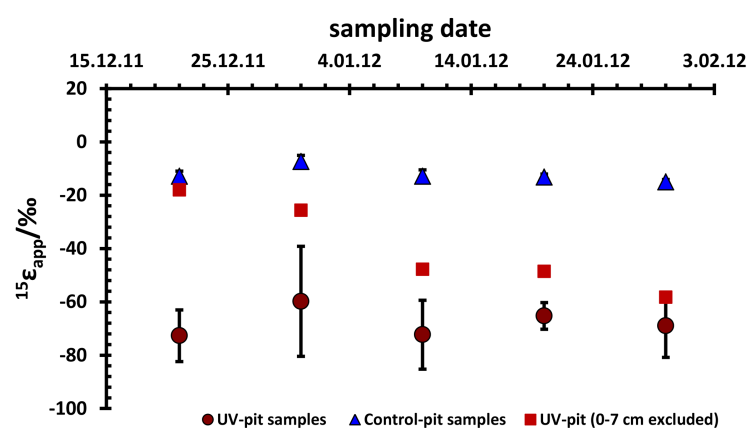

Figure 10. ${ }^{15} \varepsilon$ values determined for the control samples (triangles), UV samples excluding all samples between 0 and $7 \mathrm{~cm}$ (dashed line) and the UV samples obtained using the $\delta^{15} \mathrm{~N}$ signal to identify data points affected by non-photolytic processes (circles) rather than by excluding all $0-7 \mathrm{~cm}$ data. Note that excluding the entire top $7 \mathrm{~cm}$ data introduced an apparent trend where ${ }^{15} \varepsilon_{\text {app }}$ decreases with time. Errors are determined by the least square fit method as in Frey et al. (2009).

more positive values and then recalculated the isotopic fractionations. Accordingly, only data points between 0 and $2 \mathrm{~cm}$ were excluded for sampling events UV no. 0 to UV no. 3 . For later sampling events, UV no. 4 to UV no. 6, samples between depth of 0-6 cm were not considered in the new calculation of isotopic fractionations (shown using horizontal dashed lines in Figs. 3 and 5). The exclusion of more data points in the case of later sampling events was probably due to the fact that the external processes had more time to play a role in the modification of the near surface snow. The plots made based on these corrections are also shown in Fig. 10. ${ }^{15} \varepsilon_{\text {app }}$ values ranging from -59.8 to $-73.0 \%$ were obtained, irrespective of the sampling time. Therefore, the pattern observed under the first assumption (i.e., excluding all points in the top $7 \mathrm{~cm}$ ) introduced an apparent evolution of ${ }^{15} \varepsilon_{\text {app }}$ over time as an artifact of the analysis. The average apparent isotopic fractionation values derived using the second approach $(-67.8 \pm 12 \%)$ are in excellent agreement with previous average apparent isotopic fractionations of $-60 \pm 10 \%$ at Dome C (Frey et al., 2009) and $-59 \pm 10 \%$ for the East Antarctic Plateau (Erbland et al., 2013) (Table 3). This data exclusion procedure based on the $\delta^{15} \mathrm{~N}$ signal was applicable only to samples from sampling events between controls no. 4 and 6 as samples from the first two events (controls no. 2 and 3) showed no deviation in $\delta^{15} \mathrm{~N}$ from the expected pattern (Fig. 3), and we have calculated a ${ }^{15} \varepsilon_{\text {app }}$ value of $-12.0 \pm 1.7 \%$. As shown in Table 2, the observed change in the calculated ${ }^{15} \varepsilon_{\text {app }}$ was minor.

Based on the significant difference between the ${ }^{15} \varepsilon_{\text {app }}$ values of the control and UV samples, it is clear that the more highly negative isotopic fractionation is associated with solar UV photolysis. However, the small negative nitrogen isotopic fractionation (an average of $-12.3 \pm 1.7 \%$ ) observed for the control samples may be due to a combination of 
Table 2. The apparent nitrogen isotopic fractionations determined for both pits excluding all the samples between 0 and $7 \mathrm{~cm}$ or using the $\delta^{15} \mathrm{~N}$ signal to identify whether samples were influenced by external processes. The correlation coefficients $\left(r^{2}\right)$ and significance $(p)$ are also given for the derived ${ }^{15} \varepsilon_{\text {app }}$ values derived using the $\delta^{15} \mathrm{~N}$ signal. Note that due to insignificant change in nitrate mass and isotopic composition, the linear fits for samples no. 0 and no. 1 from both pits were only weakly correlated and are not given in Table 2 .

\begin{tabular}{lrrrr}
\hline Sampling & $\begin{array}{r}15 \\
\varepsilon_{\text {app }}( \pm 1 \sigma) / \% 0 \\
\text { no. }\end{array}$ & $\begin{array}{r}15 \\
\text { (Removing all samples } \\
\text { at a depth of } 0-7 \mathrm{~cm})\end{array}$ & $\begin{array}{r}\text { (Using the } \delta^{15} \mathrm{~N} \text { signal to } \\
\text { exclude some points } \\
\text { in the UV pit samples) }\end{array}$ & \\
& & $-72.7 \pm 9.7$ & 0.903 & 0.000292 \\
\hline UV no. 2 & $-18.0 \pm 7.3$ & $-57.2 \pm 27.9$ & 0.456 & 0.015800 \\
UV no. 3 & $-25.7 \pm 13.8$ & $-72.3 \pm 12.9$ & 0.762 & 0.000208 \\
UV no. 4 & $-47.8 \pm 10.0$ & $-65.8 \pm 5.0$ & 0.529 & 0.007300 \\
UV no. 5 & $-48.6 \pm 18.9$ & $-69.0 \pm 11.8$ & 0.792 & 0.000243 \\
UV no. 6 & $-58.3 \pm 20.0$ & $-12.9 \pm 9.7$ & 0.797 & 0.000010 \\
Control no. 2 & $-12.9 \pm 1.9$ & $-7.4 \pm 2.3$ & 0.443 & 0.006760 \\
Control no. 3 & $-7.4 \pm 2.3$ & $-17.7 \pm 28.1$ & 0.646 & 0.029300 \\
Control no. 4 & $-12.9 \pm 2.4$ & $-13.8 \pm 2.4$ & 0.767 & 0.000086 \\
Control no. 5 & $-13.2 \pm 1.1$ & & 0.884 & 0.000002 \\
Control no. 6 & $-15.0 \pm 0.9$ & & \\
\hline
\end{tabular}

minor photolysis and sublimation or desorption (which is present in the UV pit as well). Even if a comparable mass loss of nitrate was observed in the top $7 \mathrm{~cm}$ of both pits, the $\delta^{15} \mathrm{~N}$ values are significantly different (Fig. 5). As the absorption cross section of nitrate is limited at wavelengths shorter than $340 \mathrm{~nm}$, photodissociation of nitrate is not expected at wavelengths longer than $375 \mathrm{~nm}$ (i.e., the cutoff of the control plexiglass plate). However, minor contributions from the average $15 \%$ transmittance of the control plexiglass plate and/or direct solar UV photolysis at high solar zenith angles and UV light scattering by the snow could potentially have resulted in some minor photolysis in the control pit, even if no systematic bias was observed between edge and center samples. This implies that another process (e.g., sublimation of snow, desorption of nitrate) may take place, producing a significant nitrate mass change with only a minor change in isotopic composition. In a recent study of post-depositional isotopic effects in snow nitrate, it was verified that sublimation of snow leads to an overall ${ }^{15} \mathrm{~N}$ isotopic fractionation close to zero $\left(0.9 \pm 1.5 \%\right.$ at $-30{ }^{\circ} \mathrm{C}$, a temperature relevant at Dome $\mathrm{C}$ ), whereas natural snow is observed with a highly negative fractionation $\left({ }^{15} \varepsilon_{\text {app }}=-59 \pm 10 \%\right.$ ) (Erbland et al., 2013). Therefore, a mixing of the evaporative and photolytic fractionation processes could conceivably result in an isotopic fractionation on the order $-12 \%$ in the control pit. In contrast, photolysis is the dominant process in the UV pit due to the presence of unobstructed solar UV, and we have determined highly negative isotopic fractionations $\left({ }^{15} \varepsilon=-67.8 \pm 12.0 \%\right.$ o $)$. Considering the presence of multiple processes, we cannot consider the values derived from the UV pits to represent purely photolytic isotopic fractionation values but rather apparent ${ }^{15} \varepsilon_{\text {app }}$ values, impacted minimally by non-photolytic processes. Hence, the best estimate for purely photolytic isotopic fractionation $\left({ }^{15} \varepsilon_{\text {photo }}\right)$ under the current experimental setup would be the difference between the apparent isotopic fractionations determined for the UV and control pits $(-55.8 \pm 12.0 \%$ ), as both pits were exposed to identical physical processes except exposure to solar UV. This value is in good agreement with a recent laboratory study by Berhanu et al. (2014), who irradiated natural snow collected at Dome C using a UV lamp with a $320 \mathrm{~nm}$ filter (similar but not identical to field conditions); a ${ }^{15} \varepsilon_{\text {photo }}$ of $-47.9 \pm 6.8 \%$ was reported (Berhanu et al., 2014). The slightly less negative ${ }^{15} \varepsilon_{\text {photo }}$ value obtained for the laboratory experiment may be the result of an inability to fully reproduce the solar spectrum under laboratory conditions, in contrast to the field where the snow was exposed to natural solar UV.

We also made a comparison between the isotopic fractionations obtained from the field study and a theoretical estimate made using the $\triangle \mathrm{ZPE}$ shift model, as described in Frey et al. (2009) and recently modified by Berhanu et al. (2014). The newly modified model incorporates changes in width and amplitude, in addition to changes in the center wavelength, during isotopic substitution. By applying a $1 \%$ width reduction factor and an amplitude increase of $1 \%$, in addition to a shift of $+32.5 \mathrm{~cm}^{-1}$ in the center of the absorption cross section of ${ }^{15} \mathrm{NO}_{3}$ relative to ${ }^{14} \mathrm{NO}_{3}$, the authors derived an apparent ${ }^{15} \varepsilon$ value of $-55.1 \%$ o under Dome $\mathrm{C}$ conditions (Berhanu et al., 2014). Following this approach and considering the solar UV transmittance of the plexiglass plates, as well as using the solar actinic flux measured at Dome C on 7 January 2012 at 14:00 LT (Ghislan Picard, personal communication, 2013), we calculated a ${ }^{15} \varepsilon_{\text {photo }}$ value of $-52.6 \%$ or the UV-exposed pit. This value is also in agreement with the ${ }^{15} \varepsilon_{\text {photo }}$ obtained from the laboratory study but higher than the value determined for the UV pit, implying that complications arise from multiple processes in 
Table 3. Apparent isotopic fractionations $\left({ }^{15} \varepsilon_{\text {app }}\right)$ observed in previous studies compared to the results obtained here.

\begin{tabular}{lll}
\hline & ${ }^{15} \varepsilon / \%$ & Reference \\
\hline${ }^{15} \varepsilon_{\text {app }} / \% 0$ & $-53.9 \pm 9.7$ & Blunier et al. $(2005)^{\mathrm{a}}$ \\
& $-50.0 \pm 10.0($ DC 04) & Frey et al. $(2009)^{\mathrm{a}}$ \\
& $-71.0 \pm 12.0($ DC 09) & Frey et al. $(2009)^{\mathrm{a}}$ \\
& $-59.0 \pm 10.0$ & Erbland et al. $(2013)^{\mathrm{b}}$ \\
& $-67.8 \pm 12.0$ & This study \\
\hline${ }^{15}{ }_{\varepsilon_{\text {photo }} / \% 0}$ & -48.0 & Frey et al. $(2009)^{\mathrm{d}}$ \\
& $-47.9 \pm 6.8$ & Berhanu et al. $(2014)^{\mathrm{e}}$ \\
\hline
\end{tabular}

a Values determined for Dome C. ${ }^{\mathrm{b}}$ An apparent average value derived for different locations on the East Antarctic Plateau. ${ }^{c}$ The ${ }^{15} \varepsilon$ determined for the UV samples in this study. ${ }^{\mathrm{d}}$ Determined using the ZPE shift model and using the solar actinic flux of Dome $\mathrm{C}$ derived from snow TUV model. ${ }^{\mathrm{e}}$ A laboratory result observed using snow from Dome C and a Xe lamp with a UV filter at $320 \mathrm{~nm}$ (relevant to Dome C conditions) (Berhanu et al., 2014).

the field study. However, we note that the difference between the UV and control experiments brings the apparent isotopic fractionation closer to the pure photolysis isotopic fraction value $(-67.8$ to $-55.8 \%$ ) .

\subsubsection{Oxygen isotopic fractionations: ${ }^{18} \varepsilon$ and ${ }^{17} E$}

Before calculating the oxygen isotopic fractionations, we applied the same data exclusion procedure as above for $\delta^{18} \mathrm{O}$ and $\Delta^{17} \mathrm{O}$ measurements (not shown in the figures). For the control pit samples, we determined ${ }^{18} \varepsilon$ values ranging from -2.1 to $3.9 \%$ with an average value of $(0.2 \pm 2.6) \%$. These low ${ }^{18} \varepsilon$ values are due to an insignificant change in isotopic values. In contrast, the UV exposed snow samples have nearly stable ${ }^{18} \varepsilon$ values ranging from 9.0 to $13.0 \%$ and an average value of $(12.5 \pm 6.7) \%$, in good agreement with previous measurements (Table 4).

The ${ }^{17} E$ values for the control samples were not significantly different from zero, whereas the UV samples possessed ${ }^{17} E$ values of 1.1 to $2.2 \%$ with an average ${ }^{17} E$ value of $(2.2 \pm 1.4) \%$, in good agreement with previous studies (Table 4). This is probably due to the "cage effect", wherein the photoproducts resulting from the photolysis of nitrate immediately undergo isotopic exchange with the surrounding $\mathrm{OH}$ and/or water $\left(\Delta^{17} \mathrm{O} \approx 0\right)$ and reform secondary nitrate with $\Delta^{17} \mathrm{O}$ values approaching 0 (McCabe et al., 2005). However, compared to the variations observed in snow and ice below the photic zone (>5\%) (Erbland et al., 2013; Sofen et al., 2014), changes in $\Delta{ }^{17} \mathrm{O}$ due to the cage effect (ca. 2\%o) can be considered negligible. Another interesting observation is the greater scattering of the $\Delta^{17} \mathrm{O}$ observed for the UV pit, clearly indicating that the cage effect phenomenon is initiated by UV radiation.
Table 4. Compiled ${ }^{18} \varepsilon$ and ${ }^{17} E$ values obtained from this study for the UV samples and previous studies.

\begin{tabular}{lcl}
\hline${ }^{18} \varepsilon_{\mathrm{UV}}( \pm 1 \sigma) / \% 0$ & ${ }^{17} E_{\mathrm{UV}}( \pm 1 \sigma) / \% 0$ & Reference \\
\hline $6.0 \pm 3.0(\mathrm{DC} 04)$ & $1.0 \pm 0.2$ & Frey et al. $(2009)^{\mathrm{a}}$ \\
$9.0 \pm 2.0(\mathrm{DC} 09)$ & $2.0 \pm 0.6$ & Frey et al. $(2009)^{\mathrm{a}}$ \\
$8.7 \pm 2.4$ & $2.0 \pm 1.0$ & Erbland et al. $(2013)^{\mathrm{b}}$ \\
$12.5 \pm 6.7$ & $2.2 \pm 1.4$ & This study $^{\mathrm{c}}$ \\
\hline
\end{tabular}

${ }^{a}$ Determined by Frey et al. (2009) at Dome C during the summer campaigns in 2004 and 2007. ${ }^{\mathrm{b}}$ An average value determined by Erbland et al. (2013) for the East Antarctic Plateau. ${ }^{c}$ An average value determined by this study for all the UV samples.

\subsection{Depth dependence of isotopic fractionations}

For the samples collected at a depth of $7-20 \mathrm{~cm}$ from all batches and then binned together according to depth, the derived isotopic fractionations at each depth are shown in Fig. 11. We have calculated a nitrogen isotopic fractionation value ranging from -7.8 to $-23.6 \%$ ofor the control samples in the $7-16 \mathrm{~cm}$ depth range. However, the UV samples exhibited more highly negative fractionations ranging from -52.2 to $-65.9 \%$ with depth. The average ${ }^{15} \varepsilon_{\text {app }}$ value of $-59.9 \pm 24.7 \%$ o derived for these samples is in good agreement with the average apparent isotopic fractionation of $-67.9 \pm 12.0 \%$ o derived from the experimental UV-exposed pit. The large error bars in Fig. 11 are due to the small sample size and the relatively large uncertainty in the depth measurement, as all the layers might not have been at exactly the same depth during each sampling event, which may have led to the mixing of layers. The depth could also have changed over the course of the study due to the compaction of the snow with time. The insensitivity of ${ }^{15} \varepsilon_{\text {app }}$ with depth implies that, even if the number of photons decreases with depth in the snowpack, the spectrum of the solar actinic flux is not strongly altered, at least to the depth considered in this study. Berhanu et al. (2014) also observed a similar depth insensitivity of the nitrogen isotopic fractionations in their laboratory study, where snow from Dome $\mathrm{C}$ was irradiated with a UV lamp closely matching the solar irradiance encountered at Dome C. From their measurement of actinic flux with depth in a snow column, a uniform attenuation of incoming flux was observed, leading to almost constant ${ }^{15} \varepsilon$ values with depth in the snow column. The insensitivity of ${ }^{15} \varepsilon$ with depth is a useful feature for the analysis of $\delta^{15} \mathrm{~N}$ records obtained from deep ice cores used to understand past atmospheric changes, simplifying the interpretation of the $\delta^{15} \mathrm{~N}$ records associated with solar UV photolysis at different depths. Different modeling studies (such as the TRANSIT model (Erbland et al., 2015)) are currently attempting to use ice core $\delta^{15} \mathrm{~N}\left(\mathrm{NO}_{3}^{-}\right)$records to constrain historic variations in atmospheric oxidation capacity, changes in the ozone column and solar variability.

The ${ }^{18} \varepsilon$ and ${ }^{17} E$ values derived with depth also have a very weak Rayleigh fitting at lower depth (below 10-15 cm), and 


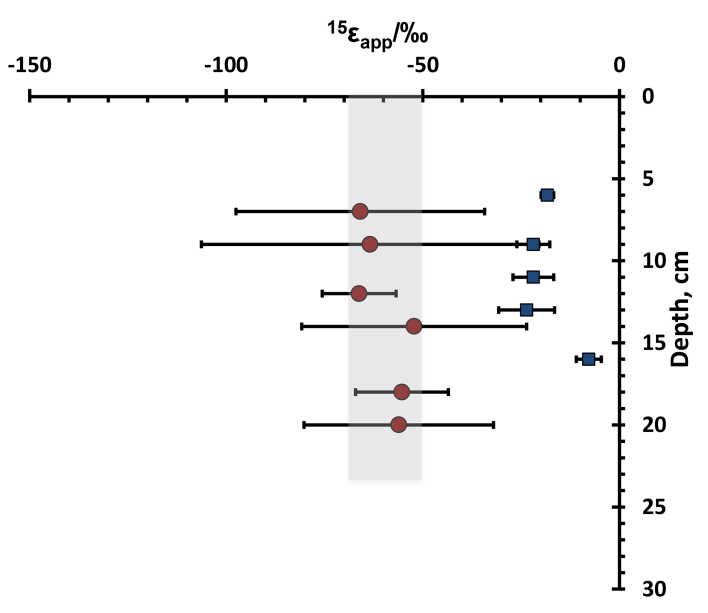

Figure 11. The depth profile of ${ }^{15_{\varepsilon}}$ for the UV pit. The ${ }^{15_{\varepsilon}} \varepsilon$ was calculated from samples collected at the same depth during each sampling event. Error bars are calculated using the least square fit method as in Frey et al. (2009). The shaded region represents the measured ${ }^{15} \varepsilon$ range of -50 to $-70 \%$.

are associated with large uncertainties. This is mainly due to the minor change in the oxygen isotopic signal, in stark contrast to the $\mathrm{N}$ isotopes, where relatively strong signals were obtained. Further studies will be required to better constrain the isotopic fractionations, especially for oxygen isotopes.

\section{Conclusions}

In this experimental study from Dome C, Antarctica, we investigated the effect of photolysis on the concentration and stable isotope ratios of nitrate in snow by comparing two identical snow pits, with one of the two exposed to solar UV. Using the combined concentration and $\delta^{15} \mathrm{~N}$ signals, we have determined an average ${ }^{15} \varepsilon_{\text {app }}$ value of $-67.8 \pm 12 \%$ o for UV-exposed samples collected at a 10-day frequency between 1 December 2011 and 30 January 2012. These values were fairly stable throughout the season and are in good agreement with previously determined isotopic fractionations at Dome C. These values are significantly different from the ${ }^{15} \varepsilon_{\text {app }}$ values obtained for the control samples $(-12.3 \pm 1.7 \%$ ). Considering the fact that the two experimental pits were exposed to identical physical processes, the difference in their apparent isotopic fractionation $(-55.8 \pm 12.0 \%$ o $)$ should be considered as the best estimate of isotopic fractionation due to photolysis. While mass loss seems to be smaller at depth in the UV-exposed pit, a stronger change in $\delta^{15} \mathrm{~N}$ was observed. This is a direct consequence of the high-fractionation factor of the photolysis process in which a small change in concentration is translated into a high variation in the isotope ratios.

When compared to the ${ }^{15} \varepsilon_{\text {photo }}$ values of $-47.9 \pm 6.8 \%$ o obtained in a laboratory experiment by Berhanu et al. (2014), where the photolytic process was isolated, the measured val- ues for the UV-exposed samples are slightly lower (i.e., more highly negative but still within the mutual error intervals). This difference might be associated with experimental design, as the laboratory conditions do not exactly replicate the solar spectrum, even if better control is possible in terms of temperature stability, and product removal relative to the field experiment. Other confounding factors may include differences in the chemical domain of nitrate (Meusinger et al., 2014) or changes due to the temperature dependence of the nitrate absorption cross section. It should also be noted that the field experiments show small influences due to nonphotolytic processes such as desorption, deposition and/or contamination by windblown snow.

We have also determined the depth dependence of the isotopic fractionations from the UV-exposed snow pit samples that were binned together according to depth and observed that the ${ }^{15} \varepsilon_{\text {app }}$ values are nearly insensitive to depth. Despite the fact that the ${ }^{15} \varepsilon_{\text {app }}$ values derived at different depths are associated with larger error bars, the observations are in good agreement with a previous laboratory study (Berhanu et al., 2014). In addition, previous studies did not show a strong change in spectral distribution of UV light as light propagates through the snow (Meusinger et al., 2014). Further study is necessary to validate such conclusions, for example via sampling different sites with same depth profiles and determining the isotopic fractionations.

It is important to reiterate some of the possible limitations of this experiment. Due to the unavoidable mechanical modification of the snow during the filling of the sample pits with windblown snow, the snow used in this study did not have exactly the same physical properties (grain size, density, compactness, optical properties, etc.) as the natural snowpack. This may have resulted in a modification of light scattering within the snowpack. Additionally, the snow used in this study possessed a nitrate concentration more than 1 order of magnitude higher than what is normally measured in snow pits at Dome $\mathrm{C}$, and this may have impacted nitrate chemistry in the experimental snow pits. However, to the best of our knowledge, our study is the first to attempt a replication of field constraints (natural shape and size, natural concentration and exposure, natural location of the nitrate in the snow grains, as well as meteorological conditions). Finally, we have not included some of the data points in the top layers of both pits due to possible complications due to multiple processes (mixing, sublimation, desorption, contamination, etc.). Hence, this procedure may also have introduced a small underestimation in our ${ }^{15} \varepsilon_{\text {app }}$ values, and this should be kept in mind when using the values obtained in this study.

The results obtained here, together with results described previously in the literature (Frey et al., 2009; Erbland et al., 2013; Berhanu et al., 2014), represent a strong body of evidence that solar UV photolysis is the most relevant postdepositional process modifying stable isotope ratios of snow nitrate at low-accumulation sites, where most deep ice cores are drilled. 


\section{The Supplement related to this article is available online at doi:10.5194/acp-15-11243-2015-supplement.}

Acknowledgements. The research leading to these results has received funding from the European Community's Seventh Framework Programme (FP7/2007-2013) under the grant agreement number 237890. LEFE-IMAGO, a scientific program of the Institut National des Sciences de l'Univers (INSU/CNRS), has also provided partial funding for this study. We would like to thank INSU for its financial support for lab experiments through its LEFE program. The Agence nationale de la recherche (ANR) is gratefully acknowledged for its financial support through the OPALE project (contract NT09-451281). The Institute Polaire Paul-Emile Victor (IPEV) supported the research and polar logistics through the program SUNITEDC No. 1011. This work has been partially supported by a grant from Labex OSUG@2020 (Investissements d'avenir - ANR10 LABX56). We would also like to thank Erwan Vince for his significant contribution in sample analysis.

Edited by: T. Bartels-Rausch

\section{References}

Aristidi, E., Agabi, K., Azouit, M., Fossat, E., Vernin, J., Travouillon, T., Lawrence, J. S., Meyer, C., Storey, J. W. V., Halter, B., Roth, W. L., and Walden, V.: An analysis of temperatures and wind speeds above Dome C, Antarctica, Astron. Astrophys., 430, 739-746, doi:10.1051/0004-6361:20041876, 2005.

Berhanu, T. A., Meusinger, C., Erbland, J., Jost, R., Bhattacharya, S. K., Johnson, M. S., and Savarino, J.: Laboratory study of nitrate photolysis in Antarctic snow. II. Isotopic effects and wavelength dependence, J. Chem. Phys., 140, 244306, doi:10.1063/1.4882899, 2014.

Blunier, T., Floch, G. L., Jacobi, H. W., and Quansah, E.: Isotopic view on nitrate loss in Antarctic surface snow, Geophys. Res. Lett., 32, L13501, doi:10.1029/2005gl023011, 2005.

Bohlke, J. K., Mroczkowski, S. J., and Coplen, T. B.: Oxygen isotopes in nitrate: new reference materials for O18:0-17:O-16 measurements and observations on nitratewater equilibration, Rapid Commun. Mass Sp., 17, 1835-1846, doi:10.1002/Rcm.1123, 2003.

Casciotti, K. L., Sigman, D. M., Hastings, M. G., Bohlke, J. K., and Hilkert, A.: Measurement of the oxygen isotopic composition of nitrate in seawater and freshwater using the denitrifier method, Anal. Chem., 74, 4905-4912, doi:10.1021/Ac020113w, 2002.

Chen, G., Davis, D., Crawford, J., Nowak, J. B., Eisele, F., Mauldin, R. L., Tanner, D., Buhr, M., Shetter, R., Lefer, B., Arimoto, R., Hogan, A., and Blake, D.: An investigation of South Pole $\mathrm{HO}_{x}$ chemistry: Comparison of model results with ISCAT observations, Geophys. Res. Lett., 28, 3633-3636, doi:10.1029/2001g1013158, 2001.

Cliff, S. S. and Thiemens, M. H.: High-Precision Isotopic Determination of the O-18 / O-16 and O-17 / O-16 Ratios in NitrousOxide, Anal. Chem., 66, 2791-2793, doi:10.1021/Ac00089a031, 1994.
Crawford, J. H., Davis, D. D., Chen, G., Buhr, M., Oltmans, S., Weller, R., Mauldin, L., Eisele, F., Shetter, R., Lefer, B., Arimoto, R., and Hogan, A.: Evidence for photochemical production of ozone at the South Pole surface, Geophys. Res. Lett., 28, 36413644, doi:10.1029/2001g1013055, 2001.

Dibb, J. E., Talbot, R. W., Munger, J. W., Jacob, D. J., and Fan, S. M.: Air-snow exchange of $\mathrm{HNO}_{3}$ and $\mathrm{NO}_{y}$ at Summit, Greenland, J. Geophys. Res.-Atmos., 103, 3475-3486, doi:10.1029/97jd03132, 1998.

Domine, F. and Shepson, P. B.: Air-snow interactions and atmospheric chemistry, Science, 297, 1506-1510, doi:10.1126/Science.1074610, 2002.

Erbland, J., Vicars, W. C., Savarino, J., Morin, S., Frey, M. M., Frosini, D., Vince, E., and Martins, J. M. F.: Air-snow transfer of nitrate on the East Antarctic Plateau - Part 1: Isotopic evidence for a photolytically driven dynamic equilibrium in summer, Atmos. Chem. Phys., 13, 6403-6419, doi:10.5194/acp-136403-2013, 2013.

Erbland, J., Savarino, J., Morin, S., France, J. L., Frey, M. M., and King, M. D.: Air-snow transfer of nitrate on the East Antarctic plateau - Part 2: An isotopic model for the interpretation of deep ice-core records, Atmos. Chem. Phys. Discuss., 15, 6887-6966, doi:10.5194/acpd-15-6887-2015, 2015.

France, J. L., King, M. D., Frey, M. M., Erbland, J., Picard, G., Preunkert, S., MacArthur, A., and Savarino, J.: Snow optical properties at Dome C (Concordia), Antarctica; implications for snow emissions and snow chemistry of reactive nitrogen, Atmos. Chem. Phys., 11, 9787-9801, doi:10.5194/acp-11-97872011, 2011.

Frey, M. M., Savarino, J., Morin, S., Erbland, J., and Martins, J. M. F.: Photolysis imprint in the nitrate stable isotope signal in snow and atmosphere of East Antarctica and implications for reactive nitrogen cycling, Atmos. Chem. Phys., 9, 8681-8696, doi:10.5194/acp-9-8681-2009, 2009.

Gallet, J.-C., Domine, F., Arnaud, L., Picard, G., and Savarino, J.: Vertical profile of the specific surface area and density of the snow at Dome C and on a transect to Dumont D'Urville, Antarctica - albedo calculations and comparison to remote sensing products, The Cryosphere, 5, 631-649, doi:10.5194/tc-5-6312011, 2011.

Grannas, A. M., Jones, A. E., Dibb, J., Ammann, M., Anastasio, C., Beine, H. J., Bergin, M., Bottenheim, J., Boxe, C. S., Carver, G., Chen, G., Crawford, J. H., Dominé, F., Frey, M. M., Guzmán, M. I., Heard, D. E., Helmig, D., Hoffmann, M. R., Honrath, R. E., Huey, L. G., Hutterli, M., Jacobi, H. W., Klán, P., Lefer, B., McConnell, J., Plane, J., Sander, R., Savarino, J., Shepson, P. B., Simpson, W. R., Sodeau, J. R., von Glasow, R., Weller, R., Wolff, E. W., and Zhu, T.: An overview of snow photochemistry: evidence, mechanisms and impacts, Atmos. Chem. Phys., 7, 43294373, doi:10.5194/acp-7-4329-2007, 2007.

Hastings, M. G., Jarvis, J. C., and Steig, E. J.: Anthropogenic Impacts on Nitrogen Isotopes of Ice-Core Nitrate, Science, 324, 1288-1288, doi:10.1126/Science.1170510, 2009.

Honrath, R. E., Peterson, M. C., Guo, S., Dibb, J. E., Shepson, P. B., and Campbell, B.: Evidence of $\mathrm{NO}_{x}$ production within or upon ice particles in the Greenland snowpack, Geophys Res Lett, 26, 695-698, doi:10.1029/1999g1900077, 1999.

Kaiser, J., Hastings, M. G., Houlton, B. Z., Rockmann, T., and Sigman, D. M.: Triple oxygen isotope analysis of nitrate using 
the denitrifier method and thermal decomposition of $\mathrm{N}_{2} \mathrm{O}$, Anal. Chem., 79, 599-607, doi:10.1021/Ac061022s, 2007.

Legrand, M. R. and Kirchner, S.: Origins and Variations of Nitrate in South Polar Precipitation, J. Geophys. Res.-Atmos., 95, 34933507, doi:10.1029/Jd095id04p03493, 1990.

Mack, J. and Bolton, J. R.: Photochemistry of nitrite and nitrate in aqueous solution: a review, J. Photoch. Photobio. A, 128, 1-13, doi:10.1016/S1010-6030(99)00155-0, 1999.

McCabe, J. R., Boxe, C. S., Colussi, A. J., Hoffmann, M. R., and Thiemens, M. H.: Oxygen isotopic fractionation in the photochemistry of nitrate in water and ice, J. Geophys. Res.-Atmos., 110, D15310, doi:10.1029/2004jd005484, 2005.

Meusinger, C., Berhanu, T. A., Erbland, J., Savarino, J., and Johnson, M. S.: Laboratory study of nitrate photolysis in Antarctic snow. I. Observed quantum yield, domain of photolysis, and secondary chemistry, J. Chem. Phys., 140, 244305, doi:10.1063/1.4882898, 2014.

Michalski, G., Savarino, J., Bohlke, J. K., and Thiemens, M.: Determination of the total oxygen isotopic composition of nitrate and the calibration of a Delta O-17 nitrate reference material, Anal. Chem., 74, 4989-4993, doi:10.1021/ac0256282, 2002.

Miller, C. E.: Photo-induced isotopic fractionation of stratospheric nitrous oxide, Abstr. Pap. Am. Chem. S., 219, U312-U312, 2000.

Morin, S., Savarino, J., Frey, M. M., Yan, N., Bekki, S., Bottenheim, J. W., and Martins, J. M. F.: Tracing the Origin and Fate of NO(x) in the Arctic Atmosphere Using Stable Isotopes in Nitrate, Science, 322, 730-732, doi:10.1126/Science.1161910, 2008.

Morin, S., Savarino, J., Frey, M. M., Domine, F., Jacobi, H. W., Kaleschke, L., and Martins, J. M. F.: Comprehensive isotopic composition of atmospheric nitrate in the Atlantic Ocean boundary layer from $65^{\circ} \mathrm{S}$ to $79^{\circ} \mathrm{N}$, J. Geophys. Res.-Atmos., 114, D05303, doi:10.1029/2008jd010696, 2009.

Röthlisberger, R., Hutterli, M. A., Wolff, E. W., Mulvaney, R., Fischer, H., Bigler, M., Goto-Azuma, K., Hansson, M. E., Ruth, U., Siggaard-Andersen, M. L., and Steffensen, J. P.: Nitrate in Greenland and Antarctic ice cores: a detailed description of post-depositional processes, Ann. Glaciol.-Ser., 35, 209-216, doi:10.3189/172756402781817220, 2002.

Savarino, J., Kaiser, J., Morin, S., Sigman, D. M., and Thiemens, M. H.: Nitrogen and oxygen isotopic constraints on the origin of atmospheric nitrate in coastal Antarctica, Atmos. Chem. Phys., 7, 1925-1945, doi:10.5194/acp-7-1925-2007, 2007.

Savarino, J., Morin, S., Erbland, J., Grannec, F., Patey, M. D., Vicars, W., Alexander, B., and Achterberg, E. P.: Isotopic composition of atmospheric nitrate in a tropical marine boundary layer, P. Natl. Acad. Sci. USA, 110, 17668-17673, doi:10.1073/pnas.1216639110, 2013.
Schmidt, J. A., Johnson, M. S., and Schinke, R.: Isotope effects in $\mathrm{N}_{2} \mathrm{O}$ photolysis from first principles, Atmos. Chem. Phys., 11, 8965-8975, doi:10.5194/acp-11-8965-2011, 2011.

Sigman, D. M., Casciotti, K. L., Andreani, M., Barford, C., Galanter, M., and Bohlke, J. K.: A bacterial method for the nitrogen isotopic analysis of nitrate in seawater and freshwater, Anal. Chem., 73, 4145-4153, 2001.

Sofen, E. D., Alexander, B., Steig, E. J., Thiemens, M. H., Kunasek, S. A., Amos, H. M., Schauer, A. J., Hastings, M. G., Bautista, J., Jackson, T. L., Vogel, L. E., McConnell, J. R., Pasteris, D. R., and Saltzman, E. S.: WAIS Divide ice core suggests sustained changes in the atmospheric formation pathways of sulfate and nitrate since the 19th century in the extratropical Southern Hemisphere, Atmos. Chem. Phys., 14, 5749-5769, doi:10.5194/acp14-5749-2014, 2014.

Turnbull, J. C., Sweeney, C., Karion, A., Newberger, T., Lehman, S. J., Tans, P. P., Davis, K. J., Lauvaux, T., Miles, N. L., Richardson, S. J., Cambaliza, M. O., Shepson, P. B., Gurney, K., Patarasuk, R., and Razlivanov, I.: Toward quantification and source sector identification of fossil fuel $\mathrm{CO}_{2}$ emissions from an urban area: Results from the INFLUX experiment, J. Geophys. Res.-Atmos., 120, 292-312, doi:10.1002/2014jd022555, 2015.

Vicars, W. C., Morin, S., Savarino, J., Wagner, N. L., Erbland, J., Vince, E., Martins, J. M. F., Lerner, B. M., Quinn, P. K., Coffman, D. J., Williams, E. J., and Brown, S. S.: Spatial and diurnal variability in reactive nitrogen oxide chemistry as reflected in the isotopic composition of atmospheric nitrate: Results from the CalNex 2010 field study, J. Geophys. Res.-Atmos., 118, 1056710588, doi:10.1002/Jgrd.50680, 2013.

Werner, R. A. and Brand, W. A.: Referencing strategies and techniques in stable isotope ratio analysis, Rapid Commun. Mass. Sp., 15, 501-519, doi:10.1002/Rcm.258, 2001.

Wolff, E. W.: Nitrate in polar ice, Nato ASI Ser. Ser. I, 30, 195-224, 1995.

Wolff, E. W.: Ice sheets and nitrogen, Philos. T. R. Soc. B, 368, 20130127, doi:10.1098/Rstb.2013.0127, 2013.

Yung, Y. L. and Miller, C. E.: Isotopic fractionation of stratospheric nitrous oxide, Science, 278, 1778-1780, doi:10.1126/Science.278.5344.1778, 1997.

Zhou, M. Y., Zhang, Z. H., Zhong, S. Y., Lenschow, D., Hsu, H. M., Sun, B., Gao, Z. Q., Li, S. M., Bian, X. D., and Yu, L. J.: Observations of near-surface wind and temperature structures and their variations with topography and latitude in East Antarctica, J. Geophys. Res.-Atmos., 114, D17115, doi:10.1029/2008jd011611, 2009. 